\title{
Investigation of Factors Affecting Preparedness of Reporting Adverse Drug Reactions among Nurses in Public and Private Hospitals in Dar Es Salaam, Tanzania
}

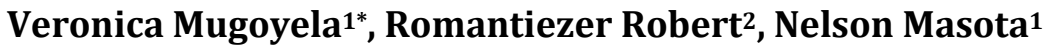 \\ ${ }^{1}$ Department of Medicinal Chemistry, Muhimbili University of Health and Allied Sciences (MUHAS), Dar es Salaam, Tanzania \\ ${ }^{2}$ Intern Pharmacist, Muhimbili National Hospital, Dar es Salaam, Tanzania \\ Email: *vmugoyela@gmail.com
}

How to cite this paper: Mugoyela, V., Robert, R. and Masota, N. (2018) Investigation of Factors Affecting Preparedness of Reporting Adverse Drug Reactions among Nurses in Public and Private Hospitals in Dar Es Salaam, Tanzania. Pharmacology \& Pharmacy, 9, 38-51.

https://doi.org/10.4236/pp.2018.91004

Received: November 17, 2017

Accepted: January 21, 2018

Published: January 24, 2018

Copyright $\odot 2018$ by authors and Scientific Research Publishing Inc. This work is licensed under the Creative Commons Attribution International License (CC BY 4.0).

http://creativecommons.org/licenses/by/4.0/

CC) (i) Open Access

\begin{abstract}
The current study assessed preparedness among nurses about reporting adverse drug reactions in public and private hospitals. Nurses in hospitals are among health providers very close to patients and are involved in the process of administering medications especially to inpatients. A cross sectional study was conducted among nurses in public and private hospitals in Dar es Salaam city in Tanzania to compare their preparedness on reporting adverse drug reactions (ADRs). A total of 384 nurses were involved in this study, of which $50 \%$ were drawn from public hospitals and $50 \%$ from private hospitals. Majority of respondents $(75.25 \%)$ in public and $84.73 \%$ in private hospitals said they have not received any training about reporting ADRs. Of the few trained nurses, $85.43 \%$ and $96.55 \%$, in public and private hospitals, respectively, said they have been trained in a seminar only once, after they started working as nurses. Respondents in public (19.17\%) and private (32.8\%) hospitals reported to stock ADRS forms (Yellow cards). Less than $50 \%$ of respondents agreed to have access to reference materials such as a text books named "Good Dispensing Practice" and a "List of Registered Medicines". Further results showed more than two third of all respondents in private $(74.25 \%)$ and public (73.5\%) hospitals reported that lack of training affects the process of reporting ADRs in terms of ability and tendency. In this study we found training, availability of Yellow cards and presence of a focal person are among important contributing factors to preparedness of reporting ADRs among nurses in public and private hospitals.
\end{abstract}

\section{Keywords}

Nurses, ADRs, Public and Private Hospitals, Yellow Cards, Training 


\section{Introduction}

Drugs carry the potential ability to produce both desirable and undesirable effects. There is no drug which is absolute safe under all circumstances of use in all patients hence adverse drug reactions may occur even when the drug is correctly selected or used [1]. Adverse drug reactions (ADRs) are responses of pharmaceutical products which are unpleasant or potentially harmful and unintended which occur at a dose normally used for prophylaxis or treatment [2]. The thorough pre-marketing investigations of a new pharmaceutical product which are carefully performed and critically assessed, do not necessarily rule out all possible side-effects and/or ADRs as well as unexpected events associated with medicines [3]. Thus, the introduction of new medicinal products into the market always carries the risks of ADRs that were not detected during pre-marketing investigations.

The causes of under reporting of ADRs in the health facilities include attitude, knowledge and behaviour of health care providers [4]. A study in Sokoto, Northern Nigeria on knowledge and attitude of physicians on reporting of ADRs showed that medical personnel had insufficient knowledge about the concept of pharmacovigilance and spontaneous ADRs reporting [5]. Other studies on knowledge, attitude and practice (KAP) suggested that the problem of under reporting and provision of quality ADRs data is beyond knowledge, attitude and behaviour rather it is caused by non-preparedness of medical personnel on reporting them. This is because of inadequate training, unavailability of tools such as ADRs forms (Yellow cards) and reference manuals to refer during reporting ADRs [6]. Further, Hazell et al. review report on ADRs insisted more works should be done to assess the impact of under-reporting in public health facilities. Moreover, the positive effects of initiatives such as internet, pharmacist/nurse reporting, direct patient reporting as well as improved training of healthcare professionals all these efforts will eventually enhance the quality and quantity of the reports [7].

The Tanzania Food and Drug Authority (TFDA), health care providers and pharmaceutical products' dealers in Tanzania are responsible for reporting ADRs of drugs on market through a process known as post market surveillance. In the process of strengthening and facilitating the ADRs monitoring and reporting system, TFDA provides pharmacovigilance awareness trainings to healthcare professionals, develops standard operating procedures (SOPs) for ADRs data handling and distributes the "Yellow cards" for spontaneous reporting [8]. In addition, guidelines for spontaneous reporting and monitoring ADRs have been developed to help healthcare professionals in understanding the procedures of reporting and the importance of ADRs monitoring [9]. The reporting covers all adverse reactions due to pharmaceutical products, biologicals (vaccines), herbal drugs, cosmetics and medical devices circulating on the Tanzanian market [9]. According to the current guidelines for monitoring and reporting ADRs in Tanzania, all health providers that interact with patients are responsible for reporting ADRs. Elsewhere in hospital settings studies have shown that 
nurses are key medical personnel in reporting adverse drug reactions because they are closest to patients comparing to other health care givers [10]. Because nurses account for majority of staff in a hospital setting, they can play a good role in reporting (ADRs) since they directly work in contact with the patients. Indeed nurses can help in the reduction of the negative effects of non reporting ADRs for newly introduced pharmaceutical products [11]. The current study aimed at investigating the factors contributing to preparedness of nurses in public and private hospitals on reporting ADRs. Specifically, the study investigated whether nurses ever received any training on reporting ADRs and the impact of lack of training; availability of reference materials and ADR reporting forms "Yellow cards"; and possible barriers in reporting ADRs among nurses.

\section{Material and Methods}

\subsection{Study Design and Sample Size}

A cross sectional study was carried out between December 2015 and April 2016 in seven conveniently selected public and private hospitals located in the Ilala municipality, Dar es Salaam. A total of 384 participants were involved in the study after considering the proportion of $50 \%$ due to a limited availability of data from related previous studies. The study participants were recruited so as to involve about 50\% each from public and private owned hospitals [12]. All employed nurses present at the time of visiting the respective facility and who consented were included in the study.

\subsection{Data Collection and Ethical Considerations}

Data were collected through self administered questionnaires (Appendix). The questionnaires were assessing contributing factors that affect preparedness of nurses on reporting (ADRs). Specific questions focused on demographic details of respondents and awareness on reporting of ADRs. Other questions aimed at gathering data on availability of in service training and seminars to nurses in public and private hospitals. The questionnaires were availed in both $S$ wahili (a native language) and English versions. Permission from the hospitals' administration and consent from each nurse were sought before involvement in the filling of the questionnaires. Ethical approval was obtained from the research and publication committee at the school of Pharmacy of the Muhimbili University of Health and Allied Sciences.

\subsection{Data Analysis}

Questionnaires were checked and edited for any inconsistence or discrepancies. Data collected was coded, entered, cleaned and analysed using the "Statistical Package for Social Sciences" (SPSS) software version 20 (SPSS Inc., Chicago, IL, USA). Results were summarized using descriptive statistics such as frequency distribution, mean, bar charts, and cross tabulation wherever necessary and a test for Chi square was done and the significance level was set at $(\mathrm{p} \leq 0.05)$. 


\section{Results}

\subsection{Social Demographic Characteristics of the Respondents}

A total of 384 respondents participated in this study from public and private hospitals. Majority of nurses were of the age between 30 to 50 years old. In public hospitals were (66.49\%) nurses in this age group as compared to $(55.79 \%)$ in private hospitals. The majority of respondents $(39.89 \%)$ in public hospitals had 6 to 10 years of work experience while in private hospitals only (32.98\%) had the same experience. The current study had revealed most experienced respondents with an experience of above 21 years, were in private hospitals (Table 1).

\subsection{Training about Reporting Adverse Drug Reactions and Role of a Focal Person}

In public hospitals $(\mathrm{n}=194,75.25 \%)$ nurses said have not been trained about reporting ADRs and those who were trained (85.43\%) received training in a seminar once, after they started working in hospitals. In private hospitals majority of the respondents $(\mathrm{n}=190,84.73 \%)$ were not trained about ADRs reporting. However, of the very few trained (96.55\%) received training once after their employment as nurses in hospitals. In public hospitals only $45.9 \%$ respondents knew the focal person to report to, issues concerning adverse drug reactions. However, majority (95.87\%) said never received any kind of instructions about reporting ADRs from focal persons. Similarly in private hospitals only (31.1\%) nurses knew the focal person and majority (98.4\%) never received any lesson from their focal persons at work place. Results of this study show majority of respondents both in public (78.4\%) and private (77.4\%) hospitals, respectively agreed that lack of trainings and seminars had a negative impact on ability to report adverse drug reactions as well as on the tendency of reporting (Table 2).

\subsection{Availability of Reference Materials to Aid the Process of Reporting}

Of the reference materials used by nurses in reporting ADRs in public hospitals Figure 1, majority (44.84\%) mentioned a textbook with a title "Good Dispensing Practice" followed by a publication known as "Guidelines For Monitoring and Reporting Adverse Drug Reactions" (39.17\%) [9] and a "List of Registered Medicine in Tanzania" (29.38\%). Similarly in private hospitals majority mentioned the textbook "Good Dispensing Practice" (50.52\%) followed by the "Guidelines For Monitoring and Reporting Adverse Drug Reactions" (46.31\%) and "List of Registered Medicine" (29.47\%). There were no other reference materials that were available to aid nurses as reporters of ADRs both in public and private hospitals.

\subsection{Availability and Use of ADRs Reporting Forms (Yellow Cards)}

Most of the respondents in public hospitals (80.8\%) didn't have access to the adverse drug reactions reporting forms (Yellow cards) and never use them for 
Table 1. Summary of social demographic characteristics of the respondents $(\mathrm{N}=384)$.

\begin{tabular}{cccc}
\hline & & \multicolumn{2}{c}{ Hospital } \\
\cline { 3 - 4 } & & Private & Public \\
\cline { 3 - 4 } Age Groups & Celow 30 & $37(19.47 \%)$ & $57(29.38 \%)$ \\
& 30 to 50 & $106(55.79 \%)$ & $129(66.49 \%)$ \\
Gender & Above 50 & $47(24.73 \%)$ & $8(4.12 \%)$ \\
& Male & $30(15.70 \%)$ & $44(22.80 \%)$ \\
Experience & Female & $161(84.30 \%)$ & $149(77.20 \%)$ \\
& 0 to 5 years & $39(20.42 \%)$ & $53(27.46 \%)$ \\
& 6 to 10 years & $63(32.98 \%)$ & $77(39.89 \%)$ \\
& 11 to 20 years & $47(24.60 \%)$ & $51(24.42 \%)$ \\
\end{tabular}

Table 2. Effects of lack of training or seminar among nurses in public and private hospitals.

\begin{tabular}{cccc}
\hline & & \multicolumn{2}{c}{ Hospital } \\
\cline { 3 - 4 } & & Private N (\%) & Public N (\%) \\
\hline \multirow{2}{*}{ Affect ability of reporting adverse drug reactions } & Yes & $147(77.4 \%)$ & $152(78.4 \%)$ \\
Affect tendency of reporting adverse drug reactions & No & $43(22.6 \%)$ & $42(21.6 \%)$ \\
Any training over the past two years & Yes & $135(71.1 \%)$ & $133(68.6 \%)$ \\
& No & $55(28.9 \%)$ & $61(31.4 \%)$ \\
& Yes & $3(1.6 \%)$ & $2(1.5 \%)$ \\
\hline
\end{tabular}

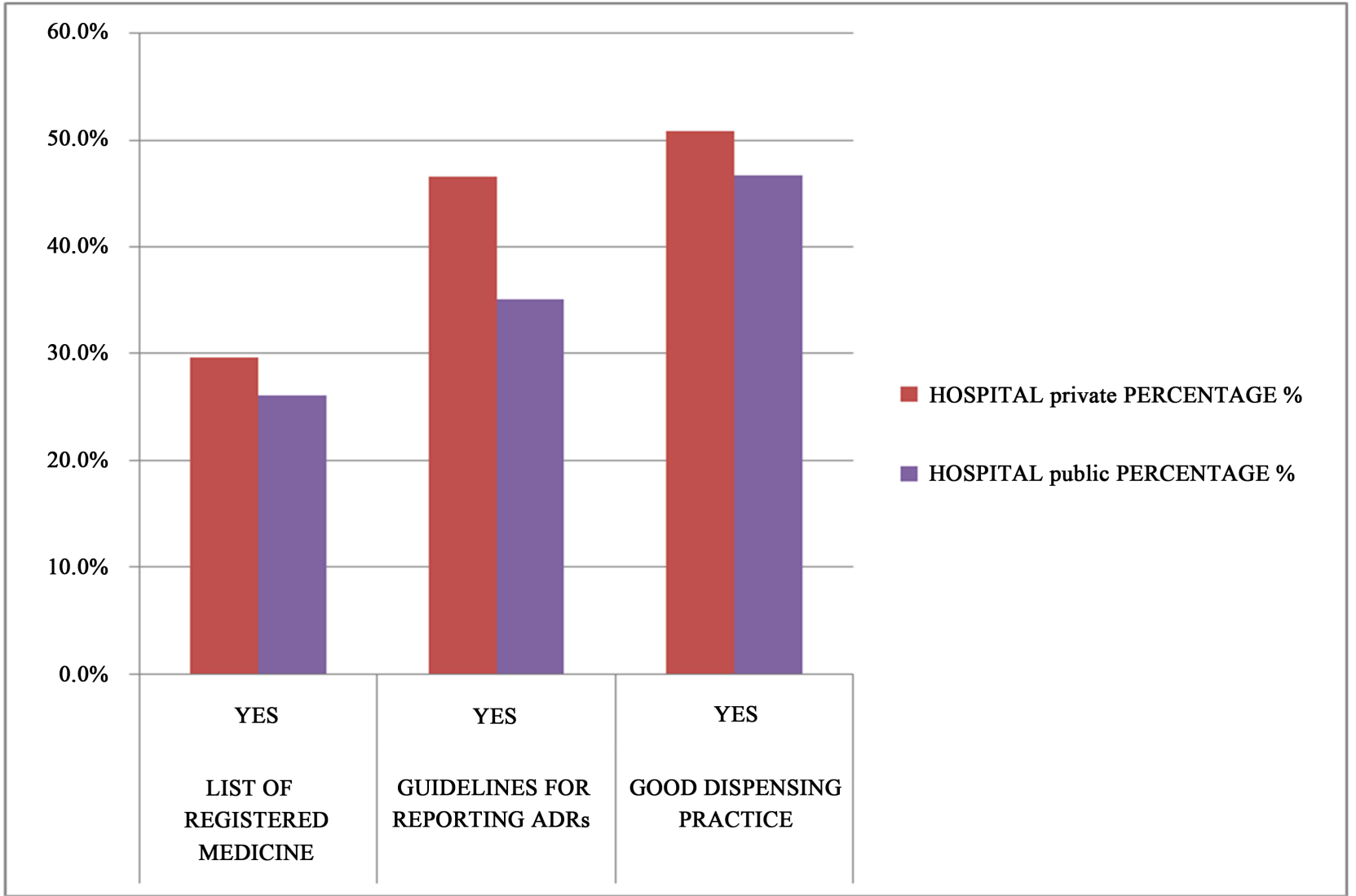

Figure 1. Shows response of materials available for references in both private and public hospital. 
reporting. The same trend was observed in private hospitals where (67.2\%) respondents didn't have access to the Yellow Cards. There was no significant relationship ( $\mathrm{p}=0.174$ and $\mathrm{p}=0.688$ ) (Table 3 ) between the availability of adverse drug reactions forms and reporting of adverse drug reactions in public and private hospitals, respectively. Table 4 shows the trend between training and reporting adverse drug reactions using ADRs reporting forms. The relationship is significant in both private hospitals $(\mathrm{p}=0.001)$ and public hospitals $(\mathrm{p}=0.01)$

\subsection{Barriers in Reporting ADRs among Nurses}

Results in Figure 2 indicate majority (61.9\%) of participants in public hospitals strongly agreed that lack of knowledge about ADRs reporting affects the process of reporting. Further (53.1\%) strongly agreed that availability of reporting forms (Yellow Cards) promotes the preparedness of adverse drug reactions reporting. However few participants strongly agreed (25.3\%) that lack of a hospital focal person affects the reporting system of ADRs in public hospitals. In private hospitals (57.4\%) of nurses strongly agreed that lack of knowledge affects preparedness of ADRs reporting and (37.4\%) strongly agreed that availability of Yellow Cards promotes the preparedness on reporting adverse drug reactions.

\section{Discussion}

The need to participate in adverse drug reactions training courses is strongly perceived among nurses despite of their years of working experience in order to develop not only competencies but also preparedness in ADRs reporting. This trend has also been observed in this study both in private and public hospital findings (Table 1 and Table 2). However in the current study the findings on relationship between training nurses about ADRs and reporting using forms (Yellow Cads) were significant both in public $(\mathrm{p}=0.01)$ and private $(\mathrm{p}=0.001)$ hospitals. Elsewhere literature has shown the importance of training nurses about ADRs and provided an increase in number of reports of suspected cases [13] [14] [15]. The

Table 3. Availability of ADRs reporting forms (yellow card) and the use of ADRs form.

\begin{tabular}{|c|c|c|c|c|c|c|c|}
\hline & & \multicolumn{3}{|c|}{ Use of $\mathrm{ADR}$ forms in public Hospitals } & \multicolumn{3}{|c|}{ Use of ADR forms in private hospitals } \\
\hline & & Yes $\mathrm{N}(\%)$ & No N (\%) & Total N (\%) & Yes N (\%) & No N (\%) & Total N (\%) \\
\hline \multirow{3}{*}{ ADR reporting form availability } & Yes & $2(8.7 \%)$ & $35(20.6 \%)$ & $37(19.2 \%)$ & $5(27.8)$ & $57(33.3 \%)$ & $62(32.8 \%)$ \\
\hline & No & $21(91.3 \%)$ & $135(79.4 \%)$ & $156(80.8 \%)$ & $13(72.2 \%)$ & $114(66.7 \%)$ & $127(67.2 \%)$ \\
\hline & & \multicolumn{3}{|c|}{$\mathrm{X}^{2}=1.849, \mathrm{df}=1, \mathrm{p}=0.174$} & \multicolumn{3}{|c|}{$\mathrm{X}^{2}=2.28, \mathrm{df}=1, \mathrm{p}=0.688$} \\
\hline
\end{tabular}

Table 4. Training and reporting of adverse drug reactions using ADRs form.

\begin{tabular}{|c|c|c|c|c|c|c|c|}
\hline & & \multicolumn{3}{|c|}{ Use of ADR forms in public Hospitals } & \multicolumn{3}{|c|}{ Use of ADR forms in private hospitals } \\
\hline & & Yes N (\%) & No N (\%) & Total N (\%) & Yes N (\%) & No N (\%) & Total N (\%) \\
\hline \multirow{3}{*}{ Nurses trained on reporting ADRs } & Yes & $4(17.4 \%)$ & $44(25.7 \%)$ & $48(24.7 \%)$ & $8(44.4 \%)$ & $21(12.2 \%$ & $29(15.3 \%)$ \\
\hline & No & $19(82.6 \%)$ & $127(74.3 \%)$ & $146(75.3 \%)$ & $10(55.6 \%)$ & $151(87.8 \%)$ & $161(84.7 \%)$ \\
\hline & & \multicolumn{3}{|c|}{$\mathrm{X}^{2}=6.638, \mathrm{df}=1, \mathrm{p}=0.01$} & \multicolumn{3}{|c|}{$\mathrm{X}^{2}=13.092, \mathrm{df}=1, \mathrm{p}=0.001$} \\
\hline
\end{tabular}




\section{BARRIERS IN REPORTING ADRs}



Figure 2. Barriers in preparedness of reporting adverse drug reaction.

procedural aspects of ADRs reporting system in hospitals requires the presence of a focal person (in charge of pharmacovigilance in the hospital). This person is an instructor responsible for keeping the reporting forms, showing how to fill them, and giving directives to whom and how to send out the reporting forms [16]. This study showed that focal persons were hardly known by the respondents in both public and private hospitals.

Moreover, it's only through filling Yellow Cards, quality information on adverse drug reactions could be obtained. The findings of this study (Table 3 ) on use of Yellow Cards corroborates with a study that was conducted in a teaching hospital in Kano, Nigeria that was determining the knowledge, attitude and practice of ADRs monitoring and reporting among healthcare workers in which only $26.3 \%$ nurses were recorded to use Yellow Cards in reporting adverse drug reactions [17]. The current study revealed and showed a number of barriers that hinder the process of reporting ADRs among nurses in public and private hospitals. These barriers include the availability of reporting forms, lack of motivation for reporting adverse drug reaction, lack of association between drug administration and event occasion, time consumptions during reporting and knowledge to fill the adverse drug reactions forms by nurses (Figure 2). Similar 
barrier of unavailability of reporting forms have been reported in a study that was conducted in United Kingdom [17]. In particular, that study indicated that giving a feedback after reporting could further encourage the health care provider in conducting the reporting [18]. ADRs reporting rate may be increased by overcoming the barriers because some of them can be solved through proper management and advertising of pharmacovigilance program such as distribution of reporting forms and appropriate guidelines hence making them widely available. The study by Mirbaha et al., identified six domains as relevant to barriers of ADRs reporting in hospitals [19]. These domains included some of the barrier observed in the current study such as "Knowledge", "Motivational factors and teamwork", Nonetheless, creating a closer relationship between nurses and ADRs reporting centers, providing nurses with proper reading materials as references to help them identify occurrence of adverse drug reactions, these can enormously enhance reporting performance. In this study the only reference materials that were widely available were a text book "Good Dispensing Practice", followed by the "Guidelines For Monitoring and Reporting Adverse Drug Reactions" and the "List of Registered Medicines". Except for the textbook, the other two references were available to less than $50 \%$ of respondents. Other reference materials such as health oriented magazines and brochures were not present in the nurses' offices visited. The nurses like other staff in the hospital need to update their knowledge on medicines hence continuing professional education is highly recommended to them.

\section{Conclusion and Recommendations}

Training, availability of Yellow cards and presence of a focal person are among important contributing factors in the preparedness of reporting ADRs among nurses both in public and private hospitals. More than two thirds of respondents said lack of training about ADRs affects both ability and tendency of reporting. Of the barriers to reporting ADRs unavailability of reporting forms (Yellow Cards) and lack of knowledge about reporting are among the barriers mentioned by more than $50 \%$ of all respondents. With regard to reference materials more than $50 \%$ of participants were exposed to and the mostly available was the textbook "Good Dispensing Practice". Because of the barriers which were identified in the current study, the Tanzania Food and Drug Authority should provide continuous and regular educational training to nurses on the importance of pharmacovigilance and their roles as health professionals, in order to improve their ability to identify and report ADRs. In addition, TFDA should make use of ADRs reporting forms a regulatory requirement for nurses in public and private hospitals. This will ensure their availability and thus promote reporting.

\section{Acknowledgements}

The authors wish to acknowledge all respondents who participated in this study. Further, authors express their gratitude to the Higher Education Student's Loans Board of Tanzania for sponsoring the current study. 


\section{Conflicts of Interest}

The authors declare no conflict of interest

\section{References}

[1] The United Republic of Tanzania, Ministry of Health, TFDA (2006) Guidelines for Monitoring and Reporting Adverse Drug.

http://apps.who.int/medicinedocs/documents/s18571en/s18571en.pdf

[2] The World Health Organization (2002) Safety of Medicines: A Guide to Detecting and Reporting Adverse Drug Reactions, Geneva. https://www.ncbi.nlm.nih.gov/pmc/articles/PMC4420988/

[3] Wooten, J. (2009) Reporting Adverse Drug Reactions. The Southern Medical Journal, 102, 345-346. http://pubmedcentralcanada.ca/pmcc/articles/PMC5139812/ https://doi.org/10.1097/SMJ.0b013e318194bc67

[4] Suyagh, M., Farah, D. and Abu Farha, R. (2014) Pharmacist's Knowledge, Practice and Attitudes toward Pharmacovigilance and Adverse Drug Reactions Reporting Process. Saudi Pharmaceutical Journal, 23, 147-153.

http://europepmc.org/abstract/med/25972734 https://doi.org/10.1016/j.jsps.2014.07.001

[5] Bello, S.O. and Umar, M.T. (2011) Knowledge and Attitudes of Physicians Relating to Reporting of Adverse Drug Reactions in Sokoto, North-Western Nigeria. Annals of African Medicine, 10, 13-18. https://doi.org/10.4103/1596-3519.76563

[6] Tew, M.M., Teoh, B.C., Mohd Baidi, A.S. and Saw, H.L. (2016) Assessment of Knowledge, Attitude and Practices of Adverse Drug Reaction Reporting among Doctors and Pharmacists in Primary Healthcare. Advances in Pharmacoepidemiology and Drug Safety, 5, 206.

[7] Hazell, L. and Shakir, S.A. (2006) Under-Reporting of Adverse Drug Reactions : A Systematic Review. Drug Safety, 29, 385-396.

https://link.springer.com/article/10.2165\%2F00002018-200629050-00003 https://doi.org/10.2165/00002018-200629050-00003

[8] Tanzania Food and Drug Authority. (2017) Reporting and Monitoring of Adverse Drug Reactions. https://www.tfda.go.tz/index/?q=adrs

[9] TFDA (2006) Guidelines for Monitoring and Reporting Adverse Drug Reactions (ADRs). http://apps.who.int/medicinedocs/documents/s18571en/s18571en.pdf

[10] Bäckström, M., Ekman, E. and Mjörndal, T. (2007) Adverse Drug Reactions Reporting by Nurses in Sweden. European Journal of Clinical Pharmacology, 63, 613-618. https://link.springer.com/article/10.1007\%2Fs00228-007-0274-8 https://doi.org/10.1007/s00228-007-0274-8

[11] Murata, A. (2014) Doctor, Nurse , Patient Relationships: Negotiating Roles and Power A Case Study of Decision-Making for C-Sections. https://deepblue.lib.umich.edu/bitstream/handle/2027.42/107761/almurata.pdf

[12] Ravindra, A., et al. (2012) Sample Size Estimation in Prevalence Studies. Indian Journal of Pediatrics, 79, 1482-1488. https://doi.org/10.1007/s12098-012-0763-3

[13] Valente, S., Murray, L. and Fisher, D. (2007) Nurses Improve Medication Safety with Medication Allergy and Adverse Drug Reports. Journal of Nursing Care Quality, 22, 322-327. https://doi.org/10.1097/01.NCQ.0000290413.04522.0b

[14] Sibilla, O. (2011) Venus Study: A Research and Education Project on Nurses and Drug Surveillance. Assistenza Infermieristica E Ricerca, 30, 6-15. http://www.air-online.it/articoli.php?archivio=yes\&vol_id=620\&id=7241 
[15] Gonzalez-Gonzalez, C., Lopez-Gonzalez, E., Herdeiro, M.T. and Figueiras, A. (2013) Strategies to Improve Adverse Drug Reactions Reporting: A Critical and Systematic Review. Drug Safety, 36, 317-328.

https://www.ncbi.nlm.nih.gov/pubmed/23640659 https://doi.org/10.1007/s40264-013-0058-2

[16] TFDA (2003) National Guidelines for Monitoring Medicines Safety. https://www.tfda.go.tz/index/sites/default/files/TFDA\%20\%28National\%20Guidelin es\%20for\%20Monitoring\%

[17] Fadare, J.O., Enwere, O.O., Afolabi, A.O., Chedi, B.A.Z. and Musa, A. (2011) Knowledge, Attitude and Practice of Adverse Drug Reactions Reporting among Healthcare Workers in a Tertiary Centre in Northern Nigeria. Tropical Journal of Pharmaceutical Research, 10, 235-242.

https://www.ajol.info/index.php/tjpr/article/view/67926 https://doi.org/10.4314/tjpr.v10i3.4

[18] Vural, F. (2014) The Knowledge, Attitude and Behaviours of Nurses about Pharmacovigilance, Adverse Drug Reactions and Adverse Event Reporting in a State Hospital. Northern Clinics of Ístanbul, 1, 147-152. https://www.ncbi.nlm.nih.gov/pmc/articles/PMC5175033/

[19] Mirbaha, et al. (2015) Perceived Barriers to Reporting Adverse Drug Events in Hospitals: A Qualitative Study Using Theoretical Domains Framework Approach. Implementation Science, 10, 110.

https://implementationscience.biomedcentral.com/articles/10.1186/s13012-015-030 $\underline{2-5}$ 


\section{Appendix}

QUESTIONNAIRE

MUHIMBILI UNIVERSITY OF HEALTH AND ALLIED SCIENCES

B PHARM IV FINAL YEAR PROJECT

QUESTIONNAIRE TO ASSES PREPAREDNESS AMONG NURSES ABOUT REPORTING ADVERSE DRUG REACTIONS IN PUBLIC HOSPITAL AND PRIVATE HOSPITALS FOR THE AIM OF IMPROVE PATIENT CARE AND SAFETY IN RELATION TO THE USE OF MEDICINES

Code No.

\section{INSTRUCTIONS:}

PLEASE USE YOUR TIME TO ANSWER THE QUESTIONS IN THIS QUESTIONNAIRE WITH YOUR BEST CAPABILITY. CIRCLE THE BEST CHOICE IN THE MULTIPLE CHOICE QUESTIONS AND KINDLY FILL IN THE SPACE PROVIDED WHEN EXPLANATIONS ARE NEEDED. IF YOU FIND DIFFICULT IN UNDERSTANDING THE QUESTION, PLEASE ASK FOR CLARIFICATION BEFORE ANSWERING

1) Age (in years)

2) Gender
a) Male
b) Female

3) Profession Experience
a) 0 - 5 years
b) 6 - 10 years
c) $11-20$ years
d) 21 and above

4) Highest education
a) Certificate
b) Diploma
c) Bachelor
d) Others (mention)

5) Is the hospital you are working at
a) Private hospital or
b) Public hospital

6) Have you ever being in training or attend seminar on adverse drug reaction?
a) Yes (complete question 7 and 15)
b) No (continue with question 16)

Please answer question number 7 to 15 if your answer in question 6 was "YES"

7) When was your first attended to the training/seminar, was it
a) Before or
b) After you got your job?(in service)

8) How many times have you attended seminar/training on adverse drug reactions within last two years?
a) None
b) Once
c) Twice
d) Thrice
e) More than thrice 


\section{OF THE REASON FOR TRAINING OR SEMINAR WAS GIVEN}

9) Due to hospital request
a) yes
b) no

10) Due to increase of adverse drug reactions occurrence
a) yes
b) no

11) Due to increase in frequency of adverse drug reaction
a) Yes
b) $\mathrm{No}$

12) Because new drugs were introduced in the market
a) Yes
b) No

13) Due to poor report (under reporting)
a) yes
b) no

14) Because government saw the need of training
a) yes
b) no

15) Order from authorized body controlling adverse reporting (TFDA)
a) yes
b) no

16) Do you know the ADRs focal person in your hospital?
a) Yes
b) No

17) Have you ever received training from him or her (focal person) regarding adverse drug reactions and reporting?
a) Yes
b) No

18) Is the lack of seminar and training affect the ability of nurses in reporting adverse drug reactions in your hospital?
a) Yes
b) No

19) Is the lack of seminar and training affect the tendency of nurses in reporting adverse drug reactions in your hospital?
a) Yes
b) No

20) Was there any adverse drug reactions training/seminar recently (for the past two year) you were asked to attend?
a) Yes
b) No

21) If there were a chance would you be willing to attend
a) Yes (complete question 22)
b) No (complete question 23)

22) If your answer was "YES" in question 21, you be willing to attend training or seminar
a) Because you were not given the chance and you need training
b) For the sake of increasing knowledge despite that you have attending it before
c) Because there is increase in number of adverse drug reactions and by getting training or seminar you would be able to report

23) If your answer was "NO" in question 21, you not be willing to attend training or seminar because 
a) Reporting adverse drug reactions is not part of my job description so training/seminar is waste of time

b) There is no significance in reporting adverse drug reactions so is the training/seminar

c) There is someone already in hospital who is responsible for reporting adverse drug reactions

24) Is your experience as a nurse enough (without training/seminar) on reporting adverse drug reaction
a) Yes
b) No

25) Materials that are available in the hospital that can be used as reference during reporting
a) List of Registered Medicine
b) Guidelines for Monitoring and Reporting Adverse Drug Reactions
c) Good Dispensing Practice

26) Are there other reference material available for nurse to use during reporting adverse drug reactions
a) Yes (complete question 27)
b) No

27) If your answer in question 26 is yes then mention them
a) Books
b) Magazine
c) Brochures
d) Others

28) Are the adverse drugs reporting form available?
a) Yes
b) No

29) How do you access the reporting form for adverse drug reactions in your hospital
a) From TFDA office though post or mails
b) Download from website of TFDA
c) From zonal information center near the hospital you are working
d) From ADRs focal person in the hospital you are working
e) I real don't know

30) Have you ever used the form for reporting adverse drug reaction?
a) Yes
b) No

31) To whom are the reports on adverse drug reactions are supposed to be send please mention
a) TFDA via post or online
b) Via zonal drug information center
c) Via ADRs focal person in the hospital am working
d) Communicate though telephone
e) I usually give to my next superior

32) Which of the above way of sending report (in question 31) do you prefer in sending Adverse Drug Reactions report?
a) ?
b) ?
c) ?
d) ?
e) ?

33) Does the availability of tools and materials affecting reporting of adverse drug reactions in your line of work?
a) Yes
b) No

34) In the following table, please respond to the statements on your left hand side by put a tick $(\sqrt{ })$ on correct response at your right hand side 
What do you think are barriers to ADRs reporting?

\begin{tabular}{|c|c|c|c|c|}
\hline Statement & Strong agree & Not sure & Disagree & Strong Disagree \\
\hline \multicolumn{5}{|l|}{ Reporting forms are not available } \\
\hline \multicolumn{5}{|l|}{ Reporting ADRs is time consuming } \\
\hline \multicolumn{5}{|l|}{ Lack of motivation for reporting } \\
\hline \multirow{2}{*}{\multicolumn{5}{|c|}{$\begin{array}{l}\text { It's hard to fill ADR report form because it requires great } \\
\text { knowledge of nature and cause of adverse drug reactions }\end{array}$}} \\
\hline & & & & \\
\hline \multicolumn{5}{|l|}{ Lack of ADRs focal person in the hospital e.g. during working hours } \\
\hline Time association between drug administration and event occasion & & & & \\
\hline
\end{tabular}

Thank you for your participation 